\title{
Método y estudio del color en la arquitectura. El caso de la iglesia de Santa Tecla de Cervera de la Cañada (Zaragoza)
}

\author{
Antonio Olmo Gracia \\ Universidad de Zaragoza ${ }^{1}$ \\ antoninianus@hotmail.com
}

\begin{abstract}
RESUMEN
El presente artículo, parte de una tesis doctoral en curso, ofrece la caracterización de los colores del revestimiento de uno de los edificios más significativos del Aragón del siglo XV: la iglesia de Santa Tecla de Cervera de la Cañada (Zaragoza), obra de Mahoma Rami (1426). El censado de colores se ha llevado a cabo a partir de la información proporcionada por las memorias de restauración, una fuente habitualmente no tenida en cuenta por los historiadores del arte, y de su puesta en relación con la documentación y literatura medieval. Este procedimiento se entiende como una labor fundamental para una aproximación ulterior a un estudio en profundidad del revestimiento.
\end{abstract}

\begin{abstract}
The present article, part of a $\mathrm{PhD}$ dissertation in process, it offers the colors characterization of the coating of one of the most significant buildings of Aragon in the 15th century: the church of Santa Tecla in Cervera de la Cañada (Saragossa), work of Mahoma Rami (1426). Registered of colors has been carried out from the information provided by the memories of restoration, a source habitually not taken in account by art historians and from its relationship with the documentation and medieval literature. This procedure is essential for a subsequent approach to a study in depth of the coating.
\end{abstract}

La iglesia de Santa Tecla de Cervera de la Cañada, pequeña localidad situada no lejos de Calatayud, es uno de los ejemplos más relevantes del arte mudéjar aragonés ${ }^{2}$. Su importancia fue destacada en la declaración de la arquitectura mudéjar de Aragón como Patrimonio de la Humanidad al reconocerla como una de sus seis obras de mayor singularidad. En gran medida esta relevancia es debida a la perfecta conservación de su revestimiento cromático original, que apenas ha sufrido

1 El presente estudio forma parte del proyecto de I+D+i El acabado en la arquitectura: Los revestimientos cromáticos y otros sistemas asociados. De la Edad Media a las intervenciones de restauración contemporáneas (HAR2009-12583), MICINN, Subdirección de Proyectos. El autor desea agradecer a D. José Félix Méndez, Jefe de la Sección de Bienes Muebles del Gobierno de Aragón, y a Dª Magdalena Gómez de Valenzuela, Directora del Archivo General de la Administración del Gobierno de Aragón, el permiso para consultar el proyecto y memoria de restauración de la iglesia de Cervera de la Cañada.

2 Pueden verse numerosas imágenes de la iglesia y su revestimiento en color en la siguiente web: http:// www.aragonmudejar.com/calatayud/cervera/cervera01.htm (consultada el 28 de marzo de 2011). 
alteraciones posteriores ${ }^{3}$. Las circunstancias de construcción de la iglesia son bien conocidas, ya que el maestro de obras, Mahoma Rami, firmó y fechó la obra. Era por entonces el principal maestro de Aragón. Durante el primer cuarto de siglo llevó a cabo algunas de las principales empresas arquitectónicas del reino, gozando de la protección del papa Benedicto XIII y de los monarcas aragoneses. El patronazgo regio explica también su labor al frente de la iglesia de Cervera. En este caso, el papel de la esposa del rey, Doña María de Castilla, fue muy importante, a juzgar por la aparición de sus armas en el interior del templo. Tanto la personalidad de su artífice como la de sus comitentes explican la gran calidad de estas obras.

El presente trabajo es parte de una tesis doctoral en curso acerca del color en la arquitectura medieval aragonesa y se integra en un proyecto de investigación interdisciplinar dedicado desde hace algunos años al estudio de los revestimientos en la arquitectura. Pretende ofrecer precisiones acerca del cromatismo en la iglesia de Cervera de la Cañada como ejemplo de un capítulo básico del procedimiento de estudio del tema de referencia, al margen de otros pasos ulteriores necesarios (filiación de motivos, referencia a posibles influencias de motivos textiles); en concreto, trata la identificación de los colores del revestimiento, fundamentalmente a partir de fuentes que no suelen ser tenidas en cuenta, como las memorias de restauración.

\section{El proceso de ejecución del revestimiento}

Las memorias de restauración constituyen una fuente de primera mano para el estudio de los edificios históricos, ya que las intervenciones suponen una ocasión privilegiada para enfrentarse al monumento. El estudio de la policromía arquitectónica histórica no puede obviar hoy día las restauraciones, momento de aplicación de medios técnicos para su estudio que dan lugar a analíticas precisas de identificación de morteros y pigmentos, entre otras cosas, que quedan recogidas en las memorias. Sin embargo, salvo excepciones, no suelen ser consultadas. Su inclusión dentro de archivos administrativos en uso y su contenido de tipo técnico en función de su finalidad al servicio de las intervenciones en los edificios, lo justifican.

Las analíticas contenidas en las memorias de restauración tienen algunos límites de cara a nuestro uso que es preciso tener en cuenta: el de su selección en parte aleatoria -las muestras se toman sin asesoramiento de un historiador; no es necesario insistir en la importancia de su participación en los procesos de restauración- o el del registro del material en la fase inicial de los trabajos, momento en el que el conocimiento del monumento es menor y en el que muchas veces no se han instalado todavía los andamios, con lo que se limitan a partes accesibles. Las analíticas

La reciente restauración del revestimiento, efectuada por Coresal, se ha limitado a labores de consolidación y limpieza. 
constituyen, ante todo, una herramienta de trabajo del restaurador, y sus necesidades no coinciden exactamente con las de un historiador del arte.

En el caso de Cervera de la Cañada, la importancia de la obra motivó una serie de analíticas bastante abundante, lo que no suele ser frecuente en este tipo de intervenciones. El proyecto y la memoria de restauración ${ }^{4}$ incluyeron una serie de analíticas generales del revestimiento mural, las yeserías y la pintura del alfarje, además de otras concretas motivadas por dudas surgidas durante el curso de la intervención. Fueron realizadas en 1999 y 2002 por D. Enrique Parra, doctor en Ciencias Químicas, y por el Departamento de Química Láser del Instituto de Química Física "Rocasolano", CSIC (Madrid) ${ }^{5}$. En conjunto, permiten conocer bastante bien numerosos aspectos técnicos de ejecución y obtener precisiones acerca de los pigmentos empleados.

El muro recibió dos capas de mortero de preparación. La inferior, de un grosor de 2-3 cm., es un mortero basto de yeso, cal y arena en proporción 10:1:1. La superior, más delgada (3-5 $\mathrm{mm}$ de espesor), tiene como componente mayoritario el yeso y gran cantidad de cola, que le otorga un color pardo claro. Esta segunda capa aflora en gran parte de la superficie del revestimiento, convirtiéndose en una forma muy económica de policromía y en un recurso que proporciona un tono cálido al conjunto de las superficies.

Sobre esta capa de preparación se trazaron con la ayuda de un objeto punzante las líneas generales de la composición y las pautas necesarias para el posterior trazado de las lacerías entrecruzadas. José Galiay recogió en sus trabajos algunos de estos esquemas previos para defender su hipótesis de que las lacerías mudéjares se obtuvieron mediante pautas sencillas y lógicas, que no precisaban un gran conocimiento matemático ${ }^{6}$. Una vez obtenido el esquema, las líneas principales se grababan sobre la superficie del yeso con un gramil (agramilado).

Sobre estos motivos se aplicó el color en capas simples, sin superposiciones, de un espesor fino, en torno a las 15-30 micras. El aglutinante es cola animal, como ocurre en los revestimientos de yeso del mudéjar aragonés, con el precedente de la

4 Archivo General de la Administración del Gobierno de Aragón (AGAGA), C-29185, "Proyecto de restauración y conservación de las pinturas murales, alfarje y yeserías de la iglesia de Santa Tecla en Cervera de la Cañada (Zaragoza)", 2 tomos, junio 1999, Coresal; y C-29186 y 29187, "Memoria de la restauración de las pinturas murales, alfarje y yeserías de la iglesia de Cervera de la Cañada en Zaragoza", 3 tomos, septiembre 2003, Coresal.

5 Ibidem., C-29185, “Análisis químico y estudio de capas de pintura de los murales, yeserías y alfarje de la iglesia de Sta. Tecla. Cervera de la Cañada (Zaragoza). Por Enrique Parra. Dr. en CC. Químicas”, por Laboratorio de análisis para la restauración y conservación de obras de arte, Villanueva de la Cañada (Madrid). Ibidem., C-29187, “Análisis químico y estudio de la superposición de capas de pintura de una muestra de la policromía del artesonado de la iglesia de Sta. Tecla en Cervera de la Cañada. Enrique Parra Crego. Dr. en CC. Químicas. 27 de mayo de 2002”; y “Análisis de muestras de la Iglesia de Santa Tecla de Cervera de la Cañada (Zaragoza). Pintura mural de estilo mudéjar. 25 de septiembre de 2002. Departamento de Química Láser. Instituto de Química Física 'Rocasolano', CSIC. Serrano 119, 28.006”.

6 J. GALIAY SARAÑANA, El lazo en el estilo mudéjar, su trazado simplista, Zaragoza, 1995, p. 23. 
pintura taifa de la Aljafería de Zaragoza ${ }^{7}$. Además del ya aludido color pardo claro de cola animal, el color del revestimiento se obtuvo a partir de una paleta de cinco pigmentos: tierra roja, bermellón, cardenillo (verde de cobre), calcita mezclada con blanco de plomo y negro carbón. El aglutinante empleado sigue siendo cola animal.

COLORES Y PIGMENTOS EN EL REVESTIMIENTO MURAL

\begin{tabular}{|c|c|}
\hline COLORES & PIGMENTOS \\
\hline Anaranjado & Tierra roja, yeso, calcita \\
\hline Rojo & Tierra roja \\
& Bermellón \\
\hline Blanco & Calcita + blanco de plomo \\
\hline Negro & Negro de carbón \\
\hline
\end{tabular}

El alfarje del coro corresponde a una misma campaña decorativa, conservando en perfecto estado su policromía. La base es una preparación de yeso muy puro. Los colores se aglutinan con huevo, aunque una analítica recoge aceite de linaza en una muestra de cardenillo. Por último, el alfarje recibió probablemente una capa de protección de aceite de linaza. Según las analíticas, el color verde y amarillo de dos de las muestras son consecuencia del amarilleamiento.

COLORES Y PIGMENTOS EN EL ALFARJE

\begin{tabular}{|c|c|}
\hline COLORES & PIGMENTOS \\
\hline Verde & Cardenillo \\
& Índigo y albayalde + barniz \\
\hline Rojo & Bermellón \\
\hline Azul & Índigo \\
\hline Amarillo & Albayalde + barniz \\
\hline
\end{tabular}

Por último, las yeserías fueron elaboradas con mortero puro de yeso que incluye calcita para retardar el fraguado e incrementar la resistencia al desgaste, cuarzo para dar volumen y facilitar su trabajo en molde o talla, y arcillas para dar color a la mezcla. Recibieron una policromía muy sutil que ha revelado la restauración. Uno de los ventanales conserva restos de haber sido recubierto con temple blanco, el corazón de algunas flores de las celosías de los antepechos conserva policromía en rojo y las situadas en el remate inferior del púlpito ligeros restos de minio. Por último, se dio una capa de protección de alúmina que impermeabiliza el yeso haciéndolo más resistente a la humedad.

7 C. RALLO GRUSS, Aportaciones a la técnica y estilística de la pintura mural en Castilla a final de la Edad Media: tradición e influencia islámica, Madrid, 1999, pp. 385-386. 


\section{La paleta del revestimiento}

Aunque las analíticas constituyen una fuente fundamental para el estudio de la policromía arquitectónica, un historiador del arte no puede quedarse en ellas. Como ha observado atinadamente Anne Vuillemard, la principal estudiosa en Francia de los revestimientos cromáticos medievales:

"Les historiens de l'art ne retranchent-ils pas trop souvent derrière ces conclusions très techniques pour éluder la question du sens? En effect, les articles consacrés à la polychromie depuis une trentaine d'années parlent de compresses, de micro-sablage, de coupes stratigraphiques mais ces informations précieuses ne peuvent suffire pour comprendre le rôle de la couleur. La polychromie n'est fréquemment envisagée que comme un ensemble de pigments et de liants n'ayant aucune incidence sur l'oeuvre servant de support. Cet élément essentiel de l'art medieval ne doit pas devenir uniquement un objet de laboratoire et c'est pourquoi une approche pluridisciplinaire est nécessaire".

La investigadora francesa no podía decirlo mejor. Las analíticas no constituyen un fin en sí mismo sino una herramienta que ha de ser interpretada con el método histórico. Como también ha puesto de relieve el por antonomasia historiador francés del color, Michel Pastoureau, el color debe ser tenido en cuenta por el historiador como un objeto de historia cultural y social.

En la iglesia de Cervera de la Cañada, la elección de los pigmentos estuvo guiada sin duda por criterios de precio y estabilidad, sobre las pautas al uso -necesitadas a su vez, es cierto, de estudios en profundidad-. Los pigmentos utilizados en el revestimiento son los más baratos, a excepción del bermellón y del minio, que destacan sobre los demás. En general, las grandes superficies a cubrir por los revestimientos motivaron el empleo de pigmentos económicos; así ocurre en los acabados medievales a base de un despiece de sillares de juntas rojas de almagra sobre fondo blanco, como los de la Catedral de Tarazona (Zaragoza) o la galería románica de San Isidoro de León ${ }^{9}$. Los textiles podían enriquecer circunstancialmente los ambientes, dándoles aún su definitivo acabado visual. La utilización masiva de pigmentos caros es muy poco frecuente: una de estas excepciones es la manda testamentaria del adelantado mayor de Castilla Gómez Manrique, que a co-

8 "Los historiadores del arte, ¿no se quedan muy a menudo tras estas conclusiones muy técnicas para eludir el problema del sentido? Efectivamente, los artículos consagrados a la policromía tras una treintena de años hablan de compresas, microarenado, de capas estratigráficas; sin embargo, estas preciosas informaciones no pueden bastar para comprender el papel del color. La policromía no es considerada frecuentemente más que como un conjunto de pigmentos y de medios que no tiene ninguna incidencia sobre la obra que le sirve de soporte. Este elemento esencial del arte medieval no debe convertirse únicamente en un objeto de laboratorio, y por este motivo es necesaria una aproximación interdisciplinar", en A. VUILLEMARD, "La polychromie des catedrales gothiques", 20 siècles en cathédrales, París, 2001, pp. 219-228, espec. p. 227.

9 C. GÓMEZ URDÁÑNZZ, "El acabado en la arquitectura. El primer revestimiento cromático del interior de la catedral de Tarazona (Zaragoza)", Actas del XIV Congreso Español de Historia del Arte (Málaga, 2002), Málaga, 2006, pp. 69-82; A. OLMO GRACIA, "Para un corpus de revestimientos lapidarios medievales: la galería románica de San Isidoro de León”, Actas del XVIII Congreso Español de Historia del Arte (Santiago de Compostela, 2010), en prensa. 
mienzos del siglo XV ordena pintar de azul de Acre toda la iglesia del monasterio de Fresdesval (Palencia), fundado por él como lugar de su último descanso ${ }^{10}$. En la siguiente tabla se aprecian los precios medios de cada pigmento en el Aragón del siglo XV de acuerdo con la documentación contemporánea ${ }^{11}$. El negro carbón no aparece porque no se refleja nunca en las cuentas, ya que es un pigmento fácil de obtener.

PRECIO DE LOS PIGMENTOS DE CERVERA DE LA CAÑADA

\begin{tabular}{|c|c|}
\hline PIGMENTO & PRECIO \\
\hline Tierra roja o almagre & 4 dineros la libra \\
\hline Blanquet o albayalde & 1 sueldo y 2-6 dineros la libra \\
\hline Verdet o cardenillo & 2'5 sueldos la libra \\
\hline Bermellón & 5-6 sueldos la libra \\
\hline Índigo & \\
\hline Minio o azarcón & 5 sueldos la libra \\
\hline
\end{tabular}

NOTA. Unidades monetarias: 1 libra $=20$ sueldos. 1 sueldo $=12$ dineros. Unidades métricas: 1 libra $=$ 12 onzas $=350{ }^{\prime} 835$ gramos. 1 onza $=29^{\prime} 236$ gramos $^{12}$.

La mayoría de la coloración de los muros se obtuvo, así pues, de los materiales más baratos, mientras que los pigmentos cuyo precio es más elevado tuvieron un papel claramente menor, con una localizada extensión: el bermellón y el minio.

Frente a la ambigüedad de los criterios con que suelen considerarse los colores en los acabados arquitectónicos medievales (producto de la escasa atención que han suscitado en la historiografía, por circunstancias y condicionantes diversos), el censado e identificación precisa de aquellos originarios, se ha entendido que aparecen en los revestimientos aragoneses medievales, con sus materiales un paso fundamental en nuestro trabajo. Este capítulo de identificación concreta y de puesta en relación con el panorama comercial y económico del Aragón del momento, acompañado de algunas otras fuentes de información contemporáneas (inventarios de bienes, tratados artísticos, o literatura) puede dar lugar al resumen de conclusiones que se ofrece a continuación, según la sistematización desarrollada en mi tesis doctoral en curso. La tabla de los colores analizados a continuación se encuentra, para su difusión a color, en la web de nuestro proyecto ${ }^{13}$.

10 J. YARZA LUACES, "La capilla funeraria hispana en torno a 1400”, La idea y el sentimiento de la muerte en la historia y el arte de la Edad Media, Santiago de Compostela, 1988, pp. 67-91, especialmente p. 90.

11 Según se razona a partir de ejemplos de compras de pigmentos en mi DEA inédito A. OLMO GRACIA, Arquitectura y revestimientos cromáticos. Obras en el contexto mudéjar de la Zaragoza de los siglos $X I V-X V$, 2009, trabajo de DEA, Depto. $\mathrm{H}^{\mathrm{a}}$. de Arte, Universidad de Zaragoza, inédito.

12 P. LARA IZQUIERDO, Sistema aragonés de pesos y medidas: la metrología histórica aragonesa y sus relaciones con la castellana, Zaragoza, 1984, p. 196.

13 http://www.carmen.gomezurdanez.com/proyecto.htm (consultada el 28 de marzo de 2011). 


\section{Fondo del paño de lacerías mixtilíneas}

El empleo de cola animal en la última capa de mortero proporcionaba varias ventajas. Protegía el revestimiento de yeso y permitía asentar la pintura. Lo más interesante es que al quedar como capa de superficie en numerosas partes del revestimiento proporcionaba una capa de color de forma muy barata, simplificando por añadidura el proceso de ejecución. Esta capa de base proporcionaba un efecto cálido y envolvente a la iglesia y permitía destacar en blanco el despiece de sillares de nervaduras, arcos y recercado de vanos y puertas, así como el ritmo de las bandas decorativas que compartimentan el despiece de ladrillos. Es un procedimiento reconocible en otros revestimientos mudéjares, como Torralba de Ribota.

Por su parte, y como se verá a continuación, las extensas superficies de color anaranjado de los ladrillos simulados se obtuvieron mediante la mezcla de ocre rojo con yeso y calcita. El ocre rojo era el más barato de los pigmentos. Costaba en el Aragón del siglo XV en torno a cuatro dineros la libra, sin contar con el hecho de que pudo ser recolectado. La cola animal costaba ligeramente más, en torno a seis dineros la libra, aunque en otras ocasiones se documentan precios inferiores ${ }^{14}$. También podía ser objeto de fabricación casera, si bien como advertía Cennino Cennini en su tratado y confirman numerosas adquisiciones, podía comprarse en las tiendas de especieros ${ }^{15}$. Con el recurso a la cola y al ocre rojo se cubrieron de color la mayor parte de las superficies del interior de la iglesia.

\section{Despiece de ladrillos}

El color de los ladrillos es una mezcla de tierra roja, yeso y calcita, con cola animal como aglutinante, una composición semejante a la del despiece latericio de un revestimiento ligeramente anterior, el de la iglesia de las Santas Justa y Rufina de Maluenda (1413). Aunque las analíticas lo describen como anaranjado, en el Aragón bajomedieval nunca se hubiera designado así. Jean Le Beghe, en su lista de colores (s. XV), define el naranja como "citrinus" ("ex croceo et rubeo mixtus"), un término que aparece en la Edad Media hispana, aunque aplicado en otros contextos ${ }^{16}$. Sin embargo, el naranja encendido se obtiene mediante el minio o azarcón (como aparece designado en la documentación aragonesa de la época), un sulfuro de plomo obtenido de la combustión del albayalde, y que aparece en las rosetas

14 Archivo Capitular de La Seo de Zaragoza (ACLSZ), Libro de fábrica de 1417-18, ff. 41r, 45r y v. Archivo de la Diputación Provincial de Zaragoza (ADPZ), Taula de Calatayud, 1445, ms. 29, 190r; ACLSZ, Libro de fabrica La Seo 1501, f. 17v; Ibidem., Libro de fabrica La Seo 1499, f. 62r.

15 C. CENNINI, Libro del arte, Madrid, 2009, p. 56.

16 "Color tyenen de cetrinos", en A. DE TALAVERA, Arcipreste de Talavera o Corbacho, Madrid, 1970, p. 184. 
del púlpito. Tal vez la designación de rosado, sino sencillamente la de ocre, sería el término más propio: Cennino Cennini habla de cómo teñir el papel de color rosado, o casi de color de melocotón, a partir de tierra verde, albayalde y sinopia (ocre rojo ${ }^{17}$, y el término aparece en los inventarios y en alguno de los contratos bajomedievales aragoneses ${ }^{18}$.

La elección de este color está en relación con la imitación de los tonos del ladrillo local. A diferencia de los acabados castellanos, donde son de color rojo, los ladrillos de los revestimientos aragoneses son siempre claros. Las cocciones daban lugar aquí a ladrillos de color claro y a una pequeña cantidad de ladrillos de color rojo $^{19}$. No obstante, el color del ladrillo simulado en los revestimientos aragoneses de los siglos XIV y XV no es homogéneo. En las obras de mediados del siglo XIV, como los revestimientos de la iglesia de Santa María de la Huerta de Magallón o de la capilla de San Martín de la Aljafería de Zaragoza se utiliza ocre amarillo para dar un color más claro aún a los ladrillos.

\section{Ladrillos resaltados en negro}

El negro empleado es de carbón. El término que aparece en la documentación coetánea es "negro", pero también, aunque de forma minoritaria, "prieto". Los negros, dada su fácil obtención, ni siquiera aparecen en las adquisiciones de pigmentos del Aragón bajomedieval. La imagen corresponde a uno de los ladrillos a tizón resaltados cromáticamente que flanquean el ladrillo rojo a soga. En contraste con los ladrillos que lo flanquean, como se verá, de bermellón, son aparentemente azules. Sin embargo, este azul es una impresión óptica, como revelan las analíticas del revestimiento mudéjar de la cercana iglesia de las santas Justa y Rufina de Maluenda:

“efecto óptico del negro carbón que engaña de lejos, pareciendo azul; el efecto se usó mucho en pintura mural, sobre todo en el fresco de época medieval en que la disponibilidad de azules resistentes al agua de cal era nula hasta la aparición del esmalte de cobalto en la segunda mitad del siglo XVI"20.

17 C. CENNINI, op. cit., pp. 50-51.

18 "Hun belo rosado leycugado guarnecido de argenteria", Archivo Histórico de Protocolos de Zaragoza (AHPZ), Pedro Marrínez de Alfocea, 1458, 23 de noviembre; "el Johan vestido de rosado fino, e las otras Marias de aquellas colores que se pertenecen", M. SERRANO SANZ, "Documentos relativos a la pintura en Aragón durante los siglos XIV y XV (Continuación)”, Revista de Bibliotecas, Archivos y Museos, 34 (1916), doc. LXXI.

19 C. GÓMEZ URDÁÑEZ, Arquitectura civil en Zaragoza en el siglo XVI, 2 vols., Zaragoza, 1987-88, vol. 1, p. 52.

20 AGAGA, "Proyecto de restauración y conservación de las pinturas murales, yeserías y cerámica de las iglesia de las Santas Justa y Rufina en Maluenda (Zaragoza)", Dpto. de Cultura y Turismo. Gobierno de Aragón. Diciembre 2001, "Análisis químico y estudio de la superposición de capas de la pintura mural de la iglesia de Santa Justa y Santa Rufina de Maluenda (Zaragoza). Enrique Parra Crego. Dr. En CC. Químicas”, pp. 61-82. 
Esta proximidad cromática entre el azul y el negro aparece constatada incluso en la literatura de la época. Don Juan Manuel, al hablar de las plumas del cuervo en uno de sus cuentos, dice que

"las vuestras péñolas son prietas, tan prieta e tan luzia es aquella pretura, que torna en india [de color azul, añil], commo péñolas de pavón, que es la más fremosa ave del mundo" 21 .

\section{Ladrillos resaltados en bermellón}

Los ladrillos a soga resaltados en rojo en el despiece fueron ejecutados con bermellón (sulfuro de mercurio). Se extrae de forma natural del cinabrio, pero también puede obtenerse a partir de la síntesis de mercurio y azufre (según receta ya conocida en Europa en el siglo VIII), como recoge el tratado de Cennino Cennini ${ }^{22}$. Se obtenía de forma sintética calentando mercurio metálico con azufre en una retorta caliente. El término con el que aparece en la documentación aragonesa de su época es "vermellon" ${ }^{23}$. Corominas opina que el término pudo pasar al castellano con probabilidad del catalán vermelló, diminutivo de vermell, encarnado, dado que por cierto documento le consta que los marinos catalanes se dedicaban a la importación de vermilione ${ }^{24}$.

Es probable que el bermellón de los revestimientos aragoneses fuera sintético y adquirido a los especieros: por las fronteras aragonesas circulan tanto mercurio como azufre y, por ejemplo, un mosen Rebolledo pasa por la taula de Calatayud en 1445 llevando azufre junto con otros pigmentos como oropimente, blanquet, sangre de dragón y bermellón, de forma que pudo dedicarse a la producción sintética de pigmentos ${ }^{25}$. Como afirma Cennini: "si quieres fatigarte, encontrarás muchas recetas, especialmente si te haces amigo de frailes" 26 .

Frente al tono agranatado del ocre rojo, el bermellón se caracteriza por un rojo encendido y brillante, cuyo atractivo motiva su elección. En la capitulación de Mahoma Rami para enlucir el cimborrio de La Seo de Zaragoza, se especifica al hablar de las orlas que el campo sea "bermello". El análisis de las pinturas mudéjares de la capilla del castillo señorial de Mozota (Zaragoza), una obra de la primera década del siglo XV, ha revelado el empleo de bermellón en los ladrillos resaltados ${ }^{27}$.

21 JUAN MANUEL, El conde Lucanor, Madrid, 1982, pp. 101-102.

22 C. CENNINI, op. cit., pp. 67-68.

23 ACLSZ, Libro de fábrica de 1417-18, ff. 31v y 34 v.

24 J. COROMINAS, Diccionario crítico etimológico castellano e hispánico, Madrid, 1984-1991, voz "bermellón".

25 ADPZ, Taula de Calatayud, 1445, ms. 29, 88v-89r.

26 C. CENNINI, op. cit., p. 68.

27 A. OLMO GRACIA y C. RALLO GRUSS, op. cit., pp. 586-587. Esta preferencia del bermellón por su rojo encendido se advierte también en las pinturas de la casa $n^{\circ} 6$ de la rue Notre-Dame de Perigueux; en cuyo revestimiento cromático se emplea el ocre rojo para zonas extensas y el cinabrio para aspectos a destacar 
No obstante, el bermellón tiene el problema del oscurecimiento en contacto con la humedad, que se ha producido en la mayoría de ladrillos resaltados de la nave de Cervera ${ }^{28}$.

\section{Azul de la policromía del alfarje}

Las analíticas de la policromía del alfarje han revelado el empleo de índigo o añil. Aunque ante todo es un tinte, suele ser empleado en los revestimientos como sustituto de los pigmentos azules (de Alemania o lapislázuli) que resultan muy caros. Se obtiene del añil, un arbusto del género indigófera. Su carácter de sustituto aparece recogido desde el siglo IX, y Cennini recoge su empleo en el capítulo LXI de su tratado:

"toma índigo de Bagdad y muélelo a conciencia con agua; mézclalo con un poco de albayalde para tabla, y con blanco de San Juan para muro. Se vuelve semejante al celeste" 29 .

El índigo se aplica en Cervera con albayalde, como se puede apreciar en la imagen y como recoge el propio Cennini, para aclarar su tono oscuro. Las adquisiciones de pigmentos de las catedrales hispanas en el siglo XV para distintas obras incluyen este colorante, como la de Sevilla ("annir"30), la de Huesca ("inde") ${ }^{31}$ o la de Zaragoza ("indi" o "indio") ${ }^{32}$. En el palacio de Hesdin de la condesa Mahaut en Artois (Francia) se encontraba a comienzos del XIV "la salle d'inde", a causa del color de sus paredes, que se lavaban y repintaban constantemente, según las cuentas. Es preciso anotar que también se utilizaba el azul de pastel como pigmento.

\section{Verde de las lacerías del coro bajo}

Lamentablemente, no existen analíticas disponibles de la policromía de los paños de lacerías entrecruzadas, en las cuales las cruces que generan los lazos se decoran en colores y verde oscuro de acuerdo con un ritmo diagonal. Existe la posibilidad de que se trate de un verde de cobre o cardenillo, el más frecuente en los revestimientos medievales, o bien de índigo que, dispuesto sobre el fondo de cola, proporciona un color verdoso.

\footnotetext{
(el vestido del rey y la decoración geométrica). P. RICARRÈRE et alii, "Dordogne. Périgueux. 6, rue NotreDame: nouvelles peintures murals", Bulletin Monumental, vol. 165-4, París, 2007, pp. 378-381.

28 M. SPRING y R. GROUT, "The blackerning of Vermilion”, National Gallery Technical Bulletin, 23 (2002), pp. 50-59.

29 C. CENNINI, ibidem, pp. 104-105.

30 J.M. MEDIANERO HERNÁNDEZ, “Aportaciones documentales sobre la técnica de la pintura mural hispalense a fines de la Edad Media”, Laboratorio de Arte, 6 (1993), pp. 67-77, en concreto p. 68.

31 Archivo Capitular de la Catedral de Huesca (ACCH), Libro de obra de 1422, f. 76v.

32 Archivo Capitular de El Pilar de Zaragoza (ACEPZ), Contados Obra 1415-1422. Libros Grandes, f. 48r y hoja suelta; ACLSZ, Libro de fábrica 1417-18, ff. 31v y 34 v.
} 
En cualquier caso, es preciso destacar esta combinación de verde y rojo, que se repite en el alfarje, muy frecuente y muy del gusto de la Edad Media, y fácilmente constatable en numerosos ejemplos prácticos, tanto en restos conservados como documentales, según ha señalado M. Pastoureau a propósito de la indumentaria medieval ${ }^{33}$. Así, la policromía de algunos sepulcros medievales hispanos se limita a estos tonos, como el de Doña Isabel de Castro y Pinós (c. 1390-1400), segunda esposa de Don Pedro Fernández de Híjar, procedente del monasterio cisterciense de Rueda (Zaragoza), hoy en el Museo Provincial: el lecho, el almohadón y la gonela que lleva la difunta son verdes, mientras que su manto es rojo; una bicromía que se repite en los frentes de la caja del sepulcro ${ }^{34}$. La policromía de la portada de la colegiata de Toro juega básicamente, sobre todo en las arquivoltas, con la alternancia entre el rojo y el verde. Por último los contratos de obras de revestimiento situadas bajo el patrocinio de la condesa Mahaut de Artois recogen con frecuencia esta combinación; entre varios ejemplos, seleccionamos dos. En el castillo de Lens, en 1307, se capitula la pintura de la techumbre en estos tonos por Robert de Rebreuve y Jean Acart ("faire les lambourdes de tout le chiele de la sale l'une vermelle, l'autre verde estincelêe de fin or" ${ }^{\text {"35}}$ ). Con Colart de Closcamp se capitula en 1325 una policromía de alternancia en los colores de las columnas de la capilla ("pour le columerch qui est entre le canchel et le moustier paindre, l'une columbe verte, l'autre vermeille"36).

El ejemplo analizado de Cervera de la Cañada plantea de forma elocuente, en definitiva, la gran importancia de las restauraciones como ocasiones privilegiadas para el estudio de los monumentos. En concreto, el estudio de los revestimientos cromáticos ha de fraguarse en el crisol de una labor interdisciplinar entre historiadores y restauradores, cuyos caminos discurren por cauces separados y mutuamente ignorados. Los medios técnicos aplicados en las restauraciones generan un conocimiento de la materialidad del revestimiento que constituyen un paso ineludible en el conocimiento de un tema de tanta importancia y que ha sido obviado hasta el momento presente, sobre el que han de incidir con posterioridad análisis de tipo formal, simbólico y social que permitan comprender y situar la obra en el contexto de la época en la plenitud de sus aspectos.

${ }^{33}$ M. PASTOUREAU, Una historia simbólica de la Edad Media occidental, Buenos Aires, 2006, p. 144.

${ }_{34}$ M.C. LACARRA DUCAY, Arte gótico en el Museo de Zaragoza, Zaragoza, 2006, p. 5.

35 J.M. RICHARD, Mahaut, comtesse d'Artois et de Bourgogne (1302-1329). Étude sur la vie privée, les arts et l'industrie, en Artois et à Paris au commencement du XIVe siècle, París, 1887, p. 345.

${ }^{36}$ Ibidem, p. 350. 